\title{
Article \\ Planners in the Future City: Using City Information Modelling to Support Planners as Market Actors
}

\author{
Emine Mine Thompson *, Paul Greenhalgh, Kevin Muldoon-Smith, James Charlton and Michal Dolník \\ Department of Architecture and Built Environment, Northumbria University, Newcastle upon Tyne, NE1 8ST, UK; \\ E-Mails: emine.thompson@northumbria.ac.uk (E.M.T), paul.greenhalgh@northumbria.ac.uk (P.G.), \\ kevin.muldoon-smith@northumbria.ac.uk (K.M.-S.), j.charlton@northumbria.ac.uk (J.C.), \\ dolnikm@study.fce.vutbr.cz (M.D.) \\ * Corresponding author
}

Submitted: 11 January 2016 | Accepted: 1 March 2016 | Published: 29 March 2016

\begin{abstract}
Recently, Adams and Tiesdell (2010), Tewdwr-Jones (2012) and Batty (2013) have outlined the importance of information and intelligence in relation to the mediation and management of land, property and urban consumers in the future city. Traditionally, the challenge for urban planners was the generation of meaningful and timely information. Today, the urban planners' challenge is no longer the timely generation of urban data, rather, it is in relation to how so much information can be exploited and integrated successfully into contemporary spatial planning and governance. The paper investigates this challenge through a commentary on two City Information Modelling (CIM) case studies at Northumbria University, UK. This commentary is grouped around four key themes, Accessibility and availability of data, accuracy and consistency of data, manageability of data and integration of data. It is also designed to provoke discussion in relation to the exploitation and improvement of data modelling and visualisation in the urban planning discipline and to contribute to the literature in related fields. The paper concludes that the production of information, its use and modelling, can empower urban planners as they mediate and contest state-market relations in the city. However, its use should be circumspect as data alone does not guarantee delivery of a sustainable urban future, rather, emphasis and future research should be placed upon interpretation and use of data.
\end{abstract}

\section{Keywords}

city information modelling; future cities; GIS; market actors; market rich intelligence; smart cities; spatial planning; urban planning

\section{Issue}

This article is part of the issue "Urban Forms and Future Cities", edited by Luca D'Acci (Erasmus University Rotterdam, The Netherlands), Tigran Haas (KTH Royal Institute of Technology, Sweden) and Ronita Bardhan (Indian Institute of Technology Bombay, India).

(C) 2016 by the authors; licensee Cogitatio (Lisbon, Portugal). This article is licensed under a Creative Commons Attribution 4.0 International License (CC BY).

\section{Introduction: Planning in the Future City}

In order to reflect on the theme for this thematic issue, Urban Forms and Future Cities, this paper focuses on one of Adams and Tiesdell's (2010) three recommended areas for capacity building in relation to the contemporary spatial planning process in the future city, that of the need for market rich information and knowledge. Justifying this focus, Adams and Tiesdell
(2010) argue that the generation and use of market rich Information and knowledge can assist in the mediation and management of land, property and urban consumers in the future city. This is because in most mature urban locations, urban development is financed by the private sector, making the ability of spatial planners to understand and influence property markets and development processes a crucial test of their effectiveness (Adams \& Tiesdell, 2010, p. 188). 
The paper analyses this situation through the lens of two City information Modelling (CIM) projects in order to consider:

- How CIM can assist in the creation of market rich information and knowledge.

- The opportunities and challenges involved in this potential relationship in the future city.

In this paper, future cities is a term used to imagine what cities themselves will be like, how they will operate, what systems will orchestrate them and how they will relate to their stakeholders (citizens, governments, businesses, investors, and others), in the future (Moir, Moonen, \& Clark, 2014).

In this imagination of the future it is no longer enough to think of the city as the sum of its land, buildings and infrastructure. The contemporary city should be engaging directly with all of its users, in order to understand and improve their lives. This is because; physical spaces, systems and users are increasingly becoming part of Mitchell's (1995) Soft City, emitting large quantities of data in real time. Indeed, why shouldn't we focus in on this area? Graham (2004, p. 35 ) indicates that, over the past 8000 years, cities have always been places where the processing of information and the creation of knowledge have been concentrated. However, this does not mean that the emergence and ubiquity of big data should be taken as a panacea for planning in the future city. Rather, big data provides the potential bedrock for new urban knowledge when it is efficiently utilized.

Illustrating this situation, from the mid-2000s, influenced by Building Information Modelling (BIM) and its success and promises for the construction industry, the term City Information Modelling (CIM) or urban information modelling, came into common use (Beirão, Duarte, Montenegro, \& Gil, 2009; Duarte, Beirão, Montenegro, \& Gil, 2012; Gil, Almeida, \& Duarte, 2011; Gil \& Duarte, 2008; Hamilton et al., 2005; Khemlani, 2007). The authors define CIM as a cross disciplinary, holistic approach to the generation of spatial data models in which the integration, application and visualisation of city data is used to manage and mediate the demand for land, property and environmental resources; the aim being to balance multiple stakeholders' needs in order to achieve sustainable and liveable cities whereby citizens play a major role in city governance. A simple way of understanding CIM is the following: if the smart city can be taken to mean the transference of the city from the analogue age to the digital one, then CIM is the practical application of this digital data in relation to the management and planning of the future city in collaboration with its citizens and stakeholders.

This paper does not attempt to illustrate a history of the smart city (for a thorough appraisal of the recent eruption in literature in relation to this debate see
Kitchin, 2014), instead it is enough to state that "the smart city concept has been around since the 1990s, but it is still a fairly new concept, evolving from, and in tandem with, technological developments...and the concepts and research areas of the 'virtual city', 'wired city', 'informational city', 'telecity', 'intelligent city', 'urban cybernetics', and the 'digital city', all of which reflects a technologically enhanced vision of a city" (Thompson, 2015, p. 501).

The analysis in this paper is focused on two ongoing CIM projects in the Department of Architecture and Built Environment at Northumbria University, namely Geo-Visualising Commercial Real Estate Markets (GV-CREM) and Virtual NewcastleGateshead (VNG). Collectively, these projects combine research in 4 specialist areas, City modelling and data (Thompson, 2015; Thompson \& Greenhalgh, 2014; Thompson \& Horne, 2010) urban visualisation (Charlton, Giddings, Thompson, \& Peverett, 2015; Giddings, Charlton, \& Horne, 2011; Horne, Thompson, \& Charlton, 2014) real estate market modelling (Greenhalgh, 2008; Greenhalgh et al., 2003; Greenhalgh \& King, 2010, 2013) urban finance and digital spatial preference modelling (Muldoon-Smith et al., 2015; Muldoon-Smith \& Greenhalgh, 2015) indicating the multi-disciplinary nature and collaborative ethos at the heart of CIM. Taken together, the learning outcomes of these two projects enable the authors to reflect upon the opportunities and challenges involved in the generation of market rich information and knowledge and help answer the underlying research question in this paper:

How can City Information Modelling (CIM) help planners to influence urban form and the future city?

The aim of this appraisal is not to critique the respective projects and their methodologies (both have strengths and weaknesses) but rather to better understand how CIM can aid urban planning through the generation of market rich information and knowledge.

These reflections are structured around four key themes:

1. Accessibility and availability of data

2. Accuracy and consistency of data

3. Manageability of data

4. Integration of data

Each theme discusses the opportunities and challenges faced by each project while the proceeding section reflects upon how deployment of CIM could be improved in the UK through our attempts to integrate the respective types of projects already introduced, into a holistic City Information Model (CIM).

Throughout, the paper reflects upon the broader concern of how urban planners can exploit the inherent potential in CIM and the challenges they face in doing so. The concluding section reflects upon the underlying research question and argues that CIM offers new 
and enhanced opportunities for planners and other professionals working in the urban environment. Particularly, in relation to the deployment of real time data into the analysis of the conditions in which key planning and resource allocation decisions are made and the appreciation of the longer term impact of such decisions. However, they should also proceed with caution because ubiquitous urban data isn't a panacea for urban problems, rather its application, through considered interpretation, is a useful tool for informing the multi stakeholder spatial planning process.

Most of the reflection in this paper will take place in relation to spatial planning in the UK with particular emphasis on England, however the reflections and conclusions in this paper will also have salience for the devolved administrations and the international urban planning audience because most mature urban locations face similar types of challenges in relation to the generation, management and application of urban data. While the findings should also be useful to planners in emerging cities in the developing world where an understanding of the urban process will be beneficial.

\section{Planning Intelligence}

According to Clifford and Tewdwr-Jones (2013) urban planning in England is increasingly defined by spatial planning, taken to mean the strategic co-ordination and inclusion of disparate policy directives and stakeholder interests in contrast to traditional forms of more static 'land use' and 'town and country planning' approaches. Yet, spatial planning's underlying evidence base is still regularly founded on historical methods of data generation and analysis. Yes, the gathering of data and the use of current technology has been an everyday working practice for planners for decades; for example in the 1980s local governments in the US started applying IT, notionally to speed up data processing but also to improve the delivery of services and to potentially increase political participation (Guthrie \& Dutton, 1992). Moreover, Booth (2003) tells us that computers have been used in the English tradition of Development Control since at least the 1970's. However, in the main, technology has been used for routine administrative tasks and gathering data, rather than as a means of managing and shaping the built environment holistically.

Examples to the contrary do exist; (Batty, 1991, 1997, 2007; Batty \& Xie, 1994; Baud, Scott, Pfeffer, Sydenstricker-Neto, \& Denis, 2014; Geertman, Ferreira Jr, Goodspeed, \& Stillwell, 2015; Gordon, Karacapilidis, Voss, \& Zauke, 1997; Laurini, 2002; Páez \& Scott, 2005; Shiode, 2000; Wu, He, \& Gong, 2010; and many others) researchers in transportation modelling, agent-based modelling, GIS, public participation, urban morphology, spatial analysis, and virtual cities, have been working in these overlapping fields for several decades now. In- deed, research has emanated from various outlets such as Computers in Urban Planning and Urban Management Conference (CUPUM), Urban Data Management Symposium (UDMS), Journal of Urban Technology, and Computer, Environments and Urban Systems Journal and many more. Yet, in the UK we believe that examples of this work are the exception, rather than the norm. Spatial planning in the UK finds itself in a state of inertia increasingly cognisant of the potential, and need for new data models (Adams \& Tiesdell, 2010; Batty, 2013; Tewdwr-Jones, 2012) to inform strategic spatial planning but still reliant on tried and tested practices of strategy development and evidence gathering.

Illustrating this situation, Turley Planning Consultancy (2015) recently surveyed 326 Local Planning Authorities and found that $50 \%$ had an employment land evidence base which pre-dated the publication of the 2012 National Planning Policy Framework (NPPF) which is the most recent review of planning in England. Planning Policy Guidance published in 2014 even recommends that ELR's do not need to be carried out anymore regularly than every 5 years, although they should be updated more regularly to account for changing circumstances. This means that in certain circumstances planning in England is quite literally conducted through the rear view mirror (Turley Planning Consultancy, 2015).

Exacerbating this situation it is quite common to see a long process of plan-led strategy formulation, traditionally through structure and unitary development plans and more recently, regional spatial strategies, local development frameworks and, laterally, local plans and core strategies. Each document goes through a long process of formulation and is underpinned by a wide selection of underlying research exercises, such as Employment Land Reviews (ELR) Strategic Housing Market Assessments (SHMA) and Strategic Housing Land Availability Assessments (SHLAA). However, many of these documents, by the time they are adopted, are years out of date. On one hand this is because of continuing macro and micro level socio-economic changes, and on the other hand, the time taken for consultation and revision and the ceaselessly changing nature of the planning system in England (Clifford \& Tewdwr-Jones, 2013) which leads to the requirement for continual reformulation before publication.

So, the challenge is to capture information resources that have the capacity to inform urban planning in a timely and accurate fashion; in order to inform the strategy formulation process and to enable planners to exert influence over the form and development of the future city. The proceeding section discusses how CIM can fill this deficit in knowledge and identifies the opportunities and challenges involved in this relationship. Consistent with Adams and Tiesdell (2010), we do not seek to contribute to the rich debate in relation to spatial planning (see Clifford \& Tewdwr- 
Jones, 2013) for an account), rather, we seek to investigate how CIM can be used as a tool by urban planners, operating as market actors, to nourish the context in which spatial planning takes place and to inform strategic planning and resource allocation decisions.

\section{The Projects}

The first project, Geo-Visualising Commercial Real Estate Markets (GV-CREM) has generated an experimental multi-criteria urban real estate model which seeks to understand the nature and vitality of commercial real estate markets in England and Wales. Initial modelling has focused on Newcastle upon Tyne (Tyne and Wear), Leeds and Croydon, which exhibit large, mature commercial real estate markets and offer the potential for inter and intra-regional comparative analysis. The underlying data is non-geometric and rests upon a GIS dataset comprising physical characteristics of commercial and industrial floorspace, occupancy status and rental value information. The database contains approximately 5billion sq. $\mathrm{ft}$.of floorspace data (1bnsq.ft.of office, $1 \mathrm{bn}$ sq. ft. of retail and $3 \mathrm{bnsq}$. ft.of industrial space) and has its origins in the National Summary Valuation Data Set and National Non Domestic Rating Returns created by the Valuation Office Agency (VOA). Taken together, these data sets represent an accurate picture of commercial and industrial real estate stock in the UK (Katyoka \& Wyatt, 2008). The model is also capable of incorporating demand approximation information secured through internet search activity. The data model is intelligent, can be disaggregated to individual buildings or aggregated to the metropolitan or functional economic area, and can be visualised in both $2 D$ and 3D (with potential for 4D longitudinal analysis using time series data). The 3D representation in Figure 1 demonstrates the utility of this model, where the height of each tower indicates the quantity of floorspace in each location and the colour denotes the relative value of that floorspace.

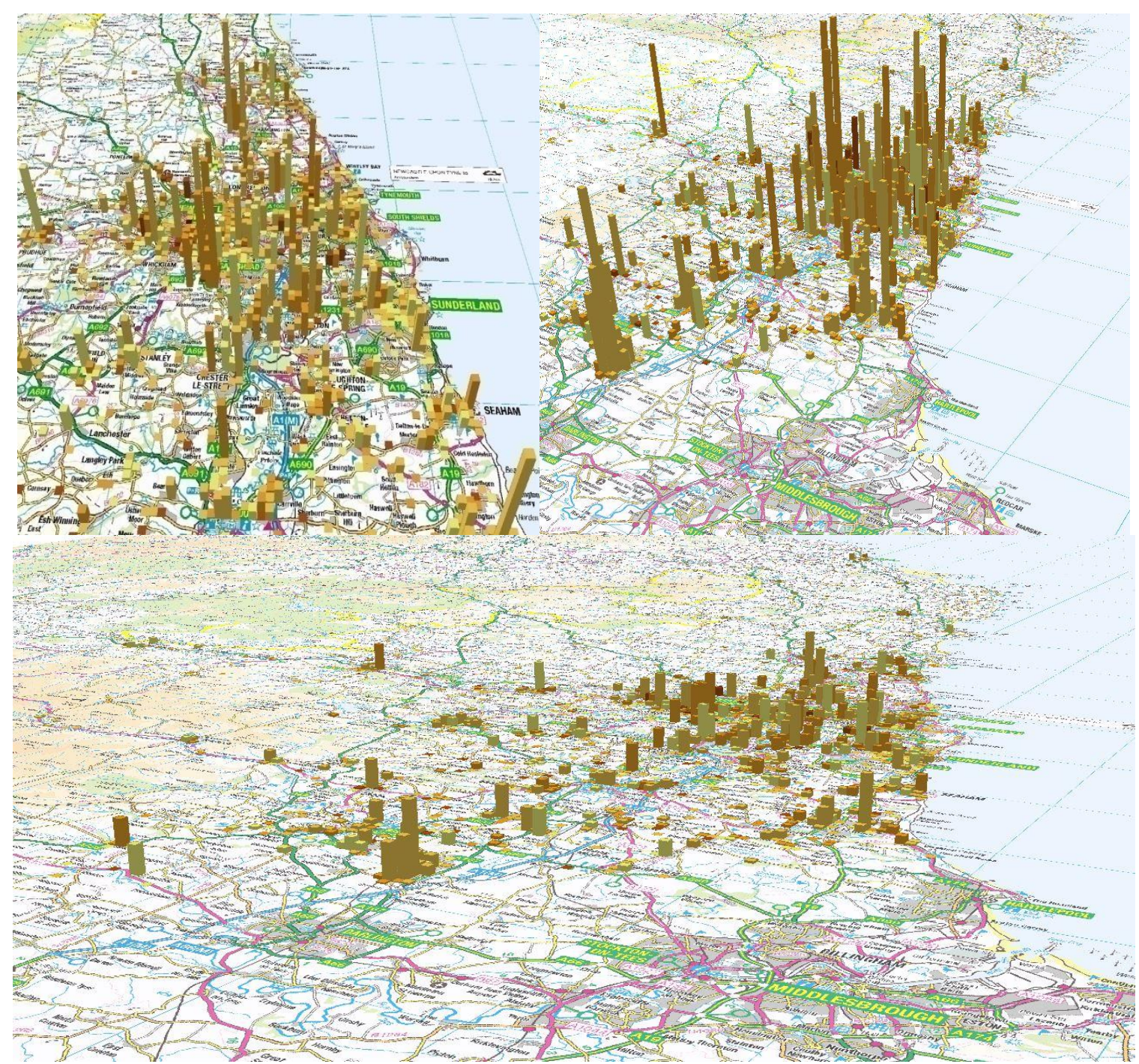

Figure 1. Topological representation of commercial real estate supply in Tyne and Wear. 
Furthermore, the representations in Figure 2 indicate the relative characteristics of commercial office space in Croydon. In this representation Croydon has been sub-divided into equal size grid squares. The dots indicate the location of commercial office property while each grid square has been scaled to indicate the relative quantity of commercial office space in each location with the colour denoting the value of office space.

In response to the report from Turley Planning Consultancy (2015) Project GE-VCREM has the ability to provide up to date employment land data while it also has the ability to inform more efficient land use planning and economic development strategy development. Following the recent turn towards fiscal decentralisation in England it also has the underlying ability to monitor and understand the impact of business rate retention and the contemporary performance of urban finance initiatives and economic stimulus programmes such as Tax Increment Financing and the continuing evolution of Enterprise Zones. This is because the basic data infrastructure of GV-CREM is founded on the English business rate system.

Finally, Figure 3 describes the spatial distribution of potential office, retail and industrial occupier preference in Leeds. The aim of this emerging project is to use internet search behaviour to approximate potential occupier preference for office, retail and industrial floorspace in Leeds (Muldoon-Smith et al., 2015). The intention is to use these urban search signals in the future to analyse the relationship between the location of office, retail and industrial premises and where potential occupiers of these types of commercial and industrial floorspace ac- tually want to locate. This research has been developed to expose potential mis-matches between where business occupiers want to locate and the physical location of office, retail and industrial business premises and in order to help guide the location of new commercial and industrial floorspace development.

The second project, Virtual Newcastle Gateshead (VNG) (Figure 4) is geometric and has been designed to visualise the urban fabric of neighbouring settlements of Newcastle upon Tyne and Gateshead in the North East of England. Initiated in 2008, in partnership with the two local authorities, the project provides a definitive, accurate, interactive city model that offers a cost effective stakeholder communication tool and way of understanding the wider implications of planning applications. VNG is; helping to streamline and increase the transparency of the planning process, supporting a number of research and enterprise activities, allowing the University to engage with a number of local and national external parties and public groups.

Both projects demonstrate the applicability of CIM to contemporary spatial planning England. On top of the perennial importance of 'location, location, location' we now have 'evidence, evidence, evidence'. Yet, the design evolution of both projects has not been straight forward, each project has been beset, to varying degrees, by issues of data accessibility and availability, data accuracy and consistency, data manageability and data integration. The following section explores these issues and reflects on the challenges involved in the integration CIM into the spatial planning practice to inform future CIM development.

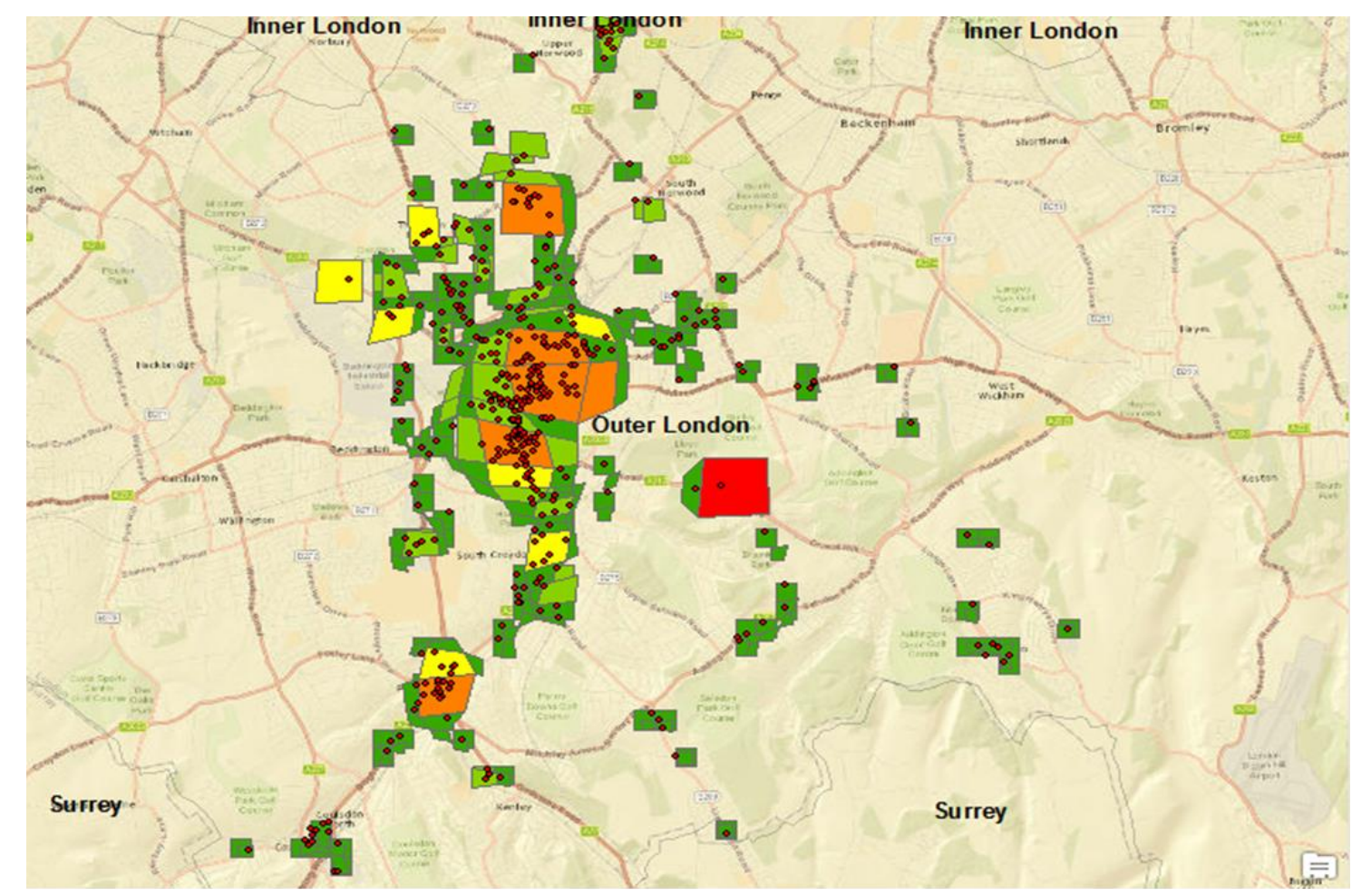

Figure 2. Relative scaling in Croydon. 


\section{Visualisation: Search Intensity}

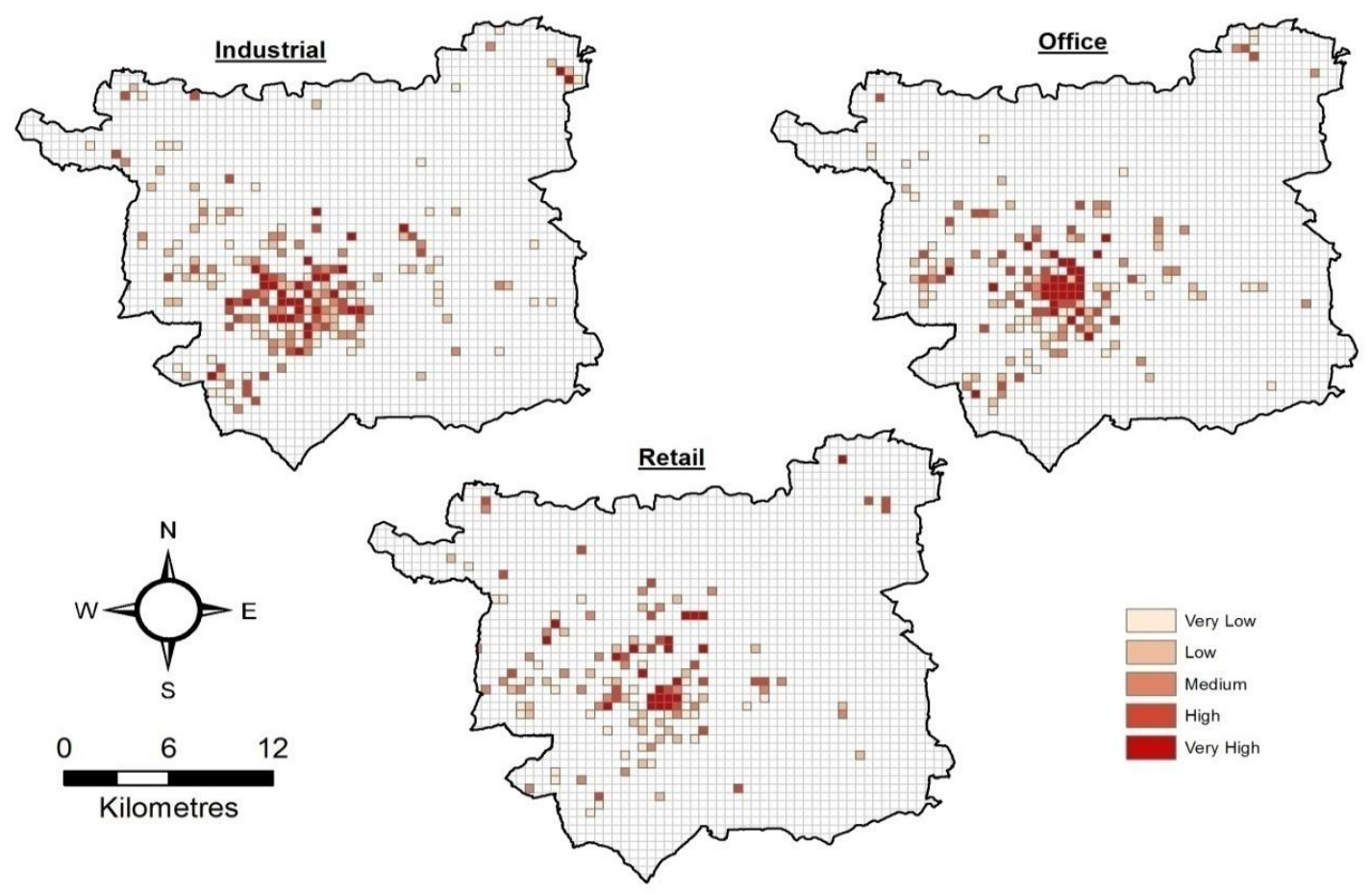

Figure 3. Potential occupier preference in Leeds.

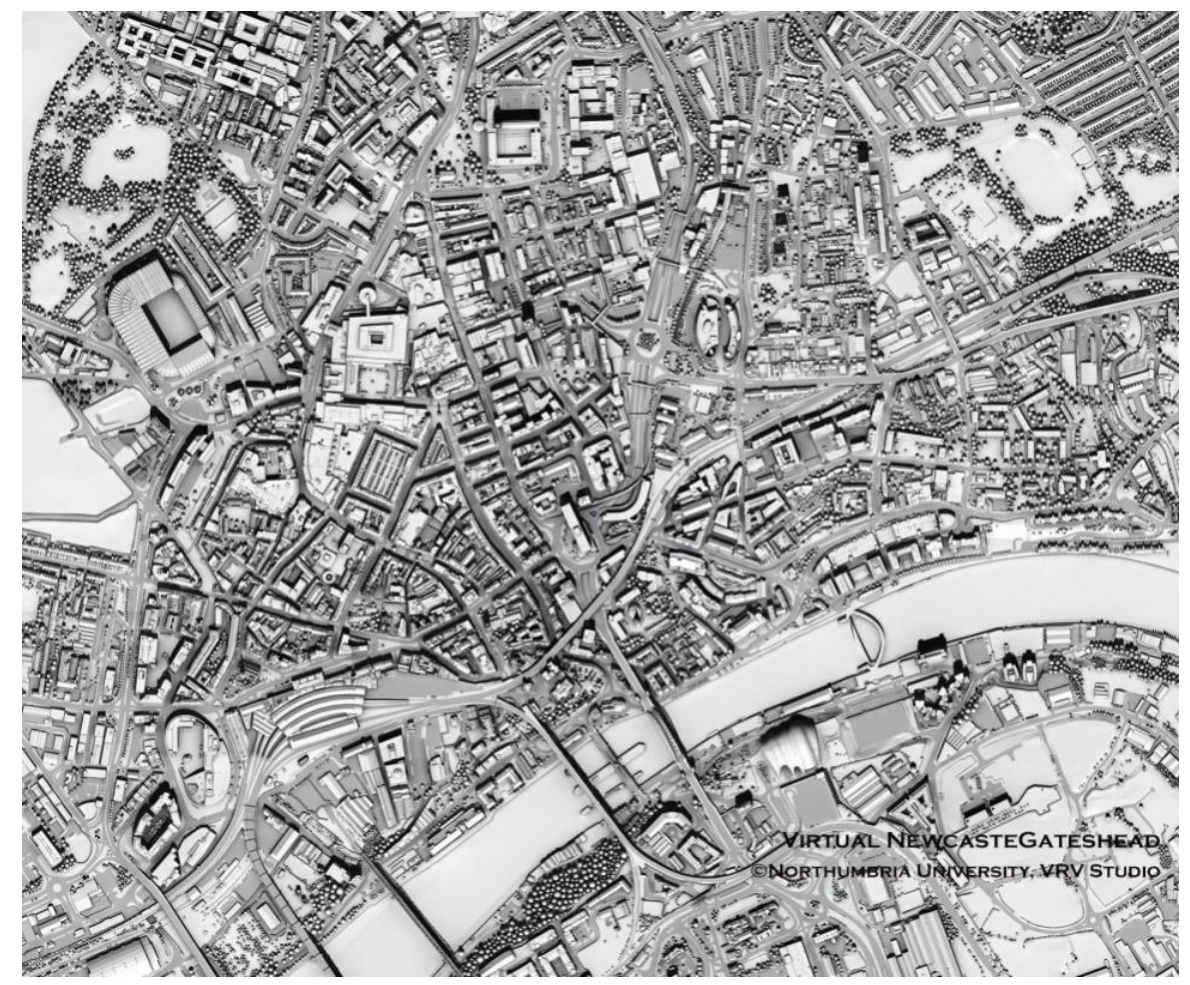

Figure 4. VNG model (central core area).

\subsection{City Information Modelling: Opportunities and Challenges}

\subsubsection{Accessibility and Availability of Data}

Making data available is one thing, doing this efficiently is another entirely. In other words, how data is published and its format informs its accessibility and future usability for research and practical purposes. Illustrating this situation, project GV-CREM had considerable difficulty accessing uniform information for its database despite the UK Government's commitment to 
open data. Illustrating this situation, the VOA, charged with creating the national summary valuation data set every five years, only release information through its internet based Agent Mode System. Immediately, this would appear to be a positive situation, however, they only release information through an individual hereditament that is an individual parcel of property that is available for rent. The hereditament can pertain to an entire building or $a$ in the case of office buildings, which are traditionally subdivided for rental purposes, a part of a building, for example a floor or suite. To put this in perspective there are 1.8 million hereditaments in England and Wales, if we place an approximate time of 1 minute per view on each individual hereditament in VOA agent mode, without sleep, it would take 4 years for one person to create an aggregated property data base for England and Wales. The solution to this issue was purchasing the information through university funds, an option open to the authors but not one that is readily available to smaller organisations and independent researchers.

Furthermore, the database also makes use of $\mathrm{Na}$ tional Non Domestic Rate Returns (NNDR) which is data related to vacant commercial properties. Access to this data is inconsistent, some local authorities publish it on a quarterly basis via their websites, and some only release it through formal request while others refuse to release it at all.

Similarly, creating a 3D city model can be a challenging task. Specialist companies use airborne acquisition and photogrammetry techniques to create these $3 \mathrm{D}$ city models. Considering the VNG project started in 2008 the accessibility to 3D data was rather limited and expensive, preventing availability of this type of data to smaller organisations and independent researchers. During the initial years of creating VNG, there were accessibility issues. These issues were generally in relation to the different and sometimes incompatible IT systems and software within and across these three organisations and remote access and version control. Encouragingly, advances in data collection techniques, computer graphics cards, processing power and 3D reconstruction methods (Gröger \& Plümer, 2012) have enabled the capture, production, storage and visualisation of more complex models an achievable goal. With new techniques and technologies increasing their availability and speed of creation, virtual city models similar to VNG are becoming more common. In fact, Morton , Horne, Dalton, \& Thompson (2012) have identified over one thousand models worldwide.

However, the issues of accessibility and availability identified in this section could be greatly assisted if public data was open source by default, without restrictions on commercial use, and made available in non-proprietary and open formats. This would be aided by national, regional and local governments publishing a list of the datasets that they do not publish as well as the ones that that they do release. Clearly, the journey toward quality open data is an on-going process. However, this debate should not only be in relation to government transparency, perhaps the onus should also be on those involved in CIM and urban planning to prove that releasing quality open data is a worthwhile activity.

\subsubsection{Accuracy and Consistency of Data}

During the initial stages of project GV-CREM an early decision was taken to omit Edinburgh and Birmingham from the case study because the data that each local authority provided was of such poor quality. Both of these locations are significant omissions from the UK case study, both containing mature commercial office markets, and is a source of considerable frustration on the researchers' part. Furthermore, different locations store and process their data in different ways and use different data storage applications which results in significant issues of consistency upon receipt of data in terms of format and the consequent time taken to refine data sets into a synthesis. This was particularly evident in the NNDR data set. The VOA data set was more consistent in terms of format. However, the information that was input into the VOA data set was inconsistent (especially in relation to address), reliant on the individual valuation officer conducting a building assessment, an issue also identified by Astbury and Thurstain-Goodwin (2014).

The VOA summary data could be immediately improved if each valuation office carried a GPS system and logged the geo-coordinates for each hereditament and building. This would counteract address information inconsistency and enable the differentiation of buildings with identical post codes. Furthermore, each building should be given a unique property reference number which can then be related to the underlying billing account reference numbers and hereditament. Currently, it is possible to subdivide a hereditament based valuation into its constituents parts, however, this facility would be exponentially more powerful if this process could be applied to entire buildings.

Furthermore, as VNG is being developed to be used within the urban planning process, confidence is required in relation to the degree of accuracy of the data. A pilot study conducted by Horne (2009) compared the accuracy of the current 3D data with the true urban form, by comparing specific views from the model with traditional photomontage and surveying techniques. Undertaking this study proved that the accuracy of the model satisfied planners from both councils (Figure 5).

\subsubsection{Manageability of Data}

This issue of data manageability rests on Garnter Analysts Doug Laney's (2001) classic big data conundrums 


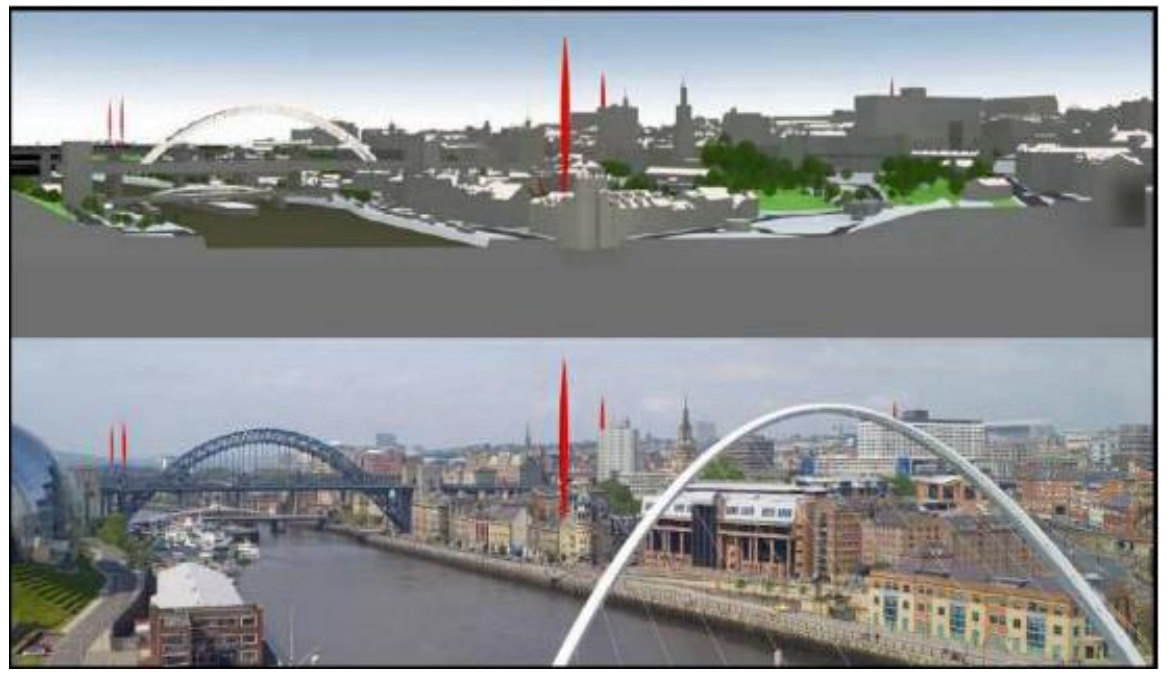

Figure 5. Verification of accuracy of Virtual Newcastle Gateshead. Source: Horne, 2009.

of volume, variety and velocity (not to mention the other two v's veracity and validity). Firstly there is just so much information that it is difficult to know where to start or when to stop. Only a few years ago the frustration was not being able to do enough, now it is possible to answer almost anything providing the volume of information can be harnessed. Then there is variety, perhaps the greatest challenge in CIM is the sheer quantity of incompatible data sets which cannot be integrated without considerable re-engineering. The consequence is the need for multiple software and hardware solutions which operate at best in unhappy compromise. The final issue is velocity, not only is there a great deal of information produced, it is also generated repetitively and increasingly in real time. One of the key challenges for spatial planning will be to harness this challenging potential as there is now real scope for planning strategy, decision making and negotiation to be evidenced in relative real time. Hitherto, it has been common place for planning authorities to rely on evidence collected sometimes decades ago. However, it is now possible for initiatives like Project GVCREM and the emerging research into digital search preference signals to evidence and justify new strategic employment land allocations and to support or defend against new development proposals with contemporary market intelligence.

To date, VNG has been delivered and managed as set of "tiles" or city square areas that are stored in a widely used 3D graphical format (DWG) to support the managing and use of the 3D data. Within each tile a naming and layering convention is used to allow distinction between roads, paths, vegetation, buildings etc. This format is ideally suited to loading selected areas of the model and performing the required visualisation and analysis tasks. However up until recently, additional interoperability of the data beyond this visual assessment is limited. This initial format is not suited to many other forms of analysis that may require bringing together data from several or all tiles, or the integration of other urban information from external databases. It is therefore the interoperability, rather than its similarity to the real world which should be the focus of such models moving forward (Bodum, Kjems, Kolar, Ilsøe, \& Overby, 2006).

\subsubsection{Integration of Data}

Perhaps the greatest challenge in relation to project GV-CREM has been the problematic nature of data integration. Ideally, all data providers should use consistent information database systems and all property data sets should contain a common unique property reference number (UPRN) with which to easily link data sets. A constant frustration throughout the research project is that there is a lot of information out there that remains un(der)exploited because of the time related difficulty associated with linking them together. For instance, the researchers would have liked to link Environmental Performance Certificate Information (EPC) data to the model and the National Land Use Data Base (NLUD). Although available to the public in nonaggregated form (EPC), and in raw format (NLUD), each assessment does not have a common identification code. Furthermore, the respective floor space measurement methods in the EPC data files did not appear to be consistent with the standard measurement of net internal area used by the VOA and NNDR systems.

Similar difficulties have been experienced with the VNG project. Although the CAD based structure of VNG and similar virtual city models are ideally suited for the loading of selected areas of the model for performing the required visualisation commonly associated with such models, additional interoperability of the data beyond this visual assessment is limited. Authors have highlighted a range of other applications that virtual city models could be used for; tourism, pedestrian and transport modelling, culture and heritage, environmen- 
tal and energy simulations (Batty et al., 2000; Döllner, Kolbe, Liecke, Sgouros, \& Teichmann, 2006; Lange \& Bishop, 2005) however current attempts to expand the application of virtual city model have been limited. Where attempts have been made, there has been a tendency for such models to be optimised for their intended end purpose, which frequently results in constraining future potential applications and therefore reducing the sustainability of the models created. The research described by Charlton (2011) and Horne, Thompson and Charlton (2014) demonstrated the interoperability of virtual city data to be utilised analytical software tools to predict the performance and visual impact of urban proposals, enabling designers and planners to gain greater understanding of performance prior to construction. However, the authors highlighted how a fully integrated approach was currently limited by the interoperability between certain selected software applications and conclude that in its initial format, VNG is not suited to many other forms of analysis that may require bringing together data from several or all tiles, or the integration of other urban information from external databases.

\section{Discussion: Creating a City Information Model (CIM)}

Digital capabilities of BIM, GIS, urban analysis, geodesign, urban design, urban data science, city information modelling and visualisation have the potential to change approaches to spatial planning. This change is arising partly because of the data infused solutions, as in Smart City applications becoming prominent and partly because requirements of holistic responses to urban problems and moving away from producing answers in silos.

The previous section discussed the opportunities and challenges involved in two CIM projects. This section explores the potential for both types of projects to be combined in order to exploit the data driven attributes of projects GV-CREM and geometric properties of VNG. The remainder of this section explores this situation through a pilot project conducted in the Department of Architecture and Built Environment at Northumbria University over the summer of 2015.

As more emphasis is put on the concept of the smart city and benefits of integrating systems and datasets in order to achieve holistic solutions, the interoperability of VNG is focusing towards the incorporation of data into the geometrical representations. We have seen evidence of this within the construction industry and the emergence of BIM. In this notion, digital three-dimensional geometrical data is linked with relative information (material, dimensions, price, stress load, etc.) in order to create a virtual building. This process aids in the development, assessment, construction and management of a building throughout its lifecycle. Although this technology is often applied to single buildings or a small group of buildings rather than city models, current research does highlight the possibilities of applying a BIM-based approach to support future city modelling and management, by utilising GIS (Döllner \& Hagedorn, 2008; Gil et al.,2011; Gil, Beirão, Moutenegro, \& Dunantie, 2010; Hudson-Smith et al., 2007; Laurini, 2002; Stojanovski, 2013; Thompson \& Horne, 2010; and many others). The proposed information-rich virtual city models developed on a database platform would contain geometric parameters, alongside relevant city information to support the assessment and visualisation of the datasets, which would offer greater capabilities in managing, accessing and utilising the advantages of the 3D geometrical data.

\section{Data Infused Virtual City Model}

A pilot project undertaken during spring of 2015 aimed to examine the feasibility of the proposed approach in relation to the smart cities agenda, the project aimed to establish the capabilities to add spatial information to the model and to utilise the model for analytical purposes. In order to form the capabilities of the geometrical data linking spatial information, the study focused to embed free and accessible datasets from the Ordnance Survey initially.

The VNG model comprises several layers: buildings, bridges, grass, roads, railroads, footpath, fences, walls, terrain, and trees. The focus of the research was on importing and utilising the buildings layer, due to its complex geometry and relevance and experimenting in attaching a variety of associated datasets. Therefore bridges, railroads, fences, walls and trees layers were excluded from the preliminary study and the grass, roads, railroads, footpath and terrain layers were combined to create a "new terrain" layer, before conversion to a TIN (Triangulated Irregular Network), a digital data structure used in GIS for the surface representation. The aim was to store the buildings as a MultiPatch feature so that one record in the database corresponds with one building. Unfortunately, the structure of the VNG dataset did not allow for this aim to be fully realised; due to the initial 3D modelling techniques used, the individual buildings are not always defined as standalone entities and in many cases they belong to a block of buildings, therefore matching the address data to a specific building became problematic.

Similarly, the research established that due to the way VNG was modelled, the geometry of the buildings had a number of defects; unnecessary polygons and surfaces which were not closed. Although this is not a barrier in the usage of the model itself for city visualisation purposes, it impairs the performance of the 3D experience. Despite a number of attempts to try and resolve the aforementioned issues within the GIS software, via more automated and scripted routes, a useable solution has yet to be achieved. As such, it was es- 
tablished that a reasonable way to fix this problem is to edit the geometry directly in CAD programme which offers a more powerful set of editing tools. If similar models are to be commonly used within GIS platforms in the future, automated geometry cleaning must be prioritised before importing into the GIS. However, by deriving and embedding some basic geometrical information; height, elevation, area, etc. this experimental project still achieved some impressive outcomes in spatial-visual analysis terms such as skyline, line of sight, construct sight lines, skyline barrier, sunshadow volume, etc. illustrated by Figure 6 (a-f).

From the Ordnance Survey, we utilized; wards, districts and streets data types within the boundary of VNG. By embedding this information within the context of VNG, it became possible to query for example; which ward certain building belongs to. By combining this knowledge with the derived geometrical data (height, elevation, etc.), it is possible to analyse which building is the highest or lowest in a particular ward, district or street.

This approach was sufficient for establishing the scope of the proposed approach and highlights the possibilities of what could be done with more and different types of data. For example rent and tax data would make it possible to find out the most expensive part of the city or a certain ward. With the recent record breaking rain fall in UK, flood damage can be determined by using the elevation of the buildings and the height of water level before hand and preparations can be done accordingly. VNG and similar virtual city models clearly have a big potential if GIS approach is to be adopted. Transferring the model to City GML format and embedding spatial information can also produce very useful outcomes. For example the resulting model can serve as an exchange platform and would also greatly extend the usage of the virtual city model.

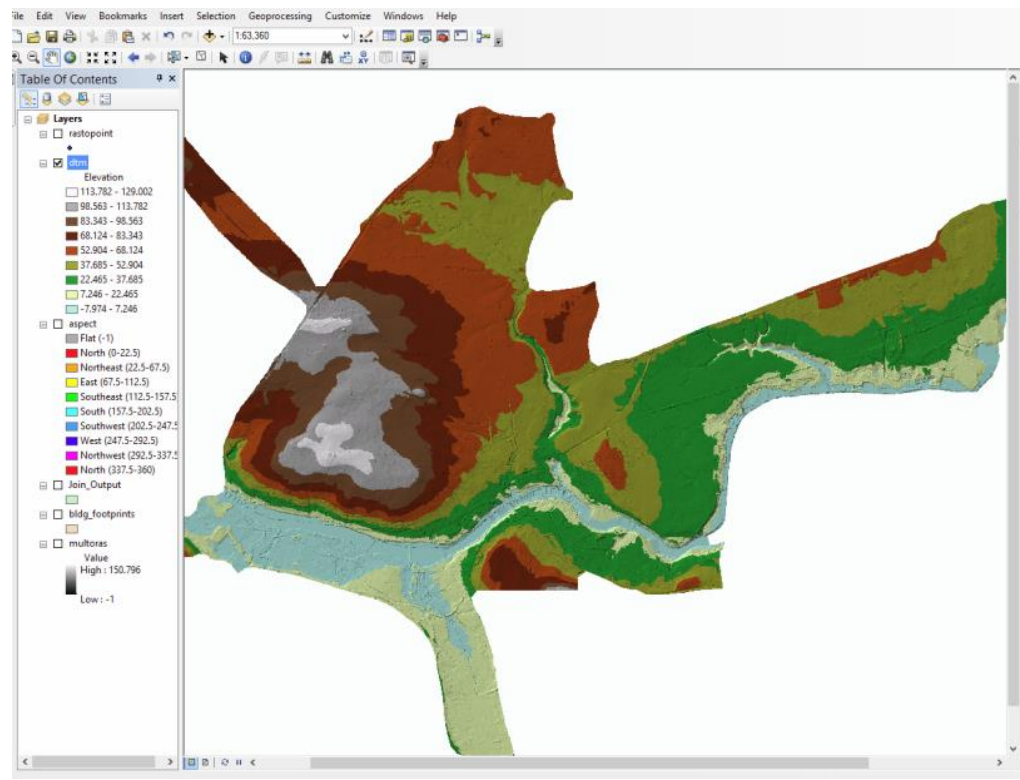

(a)

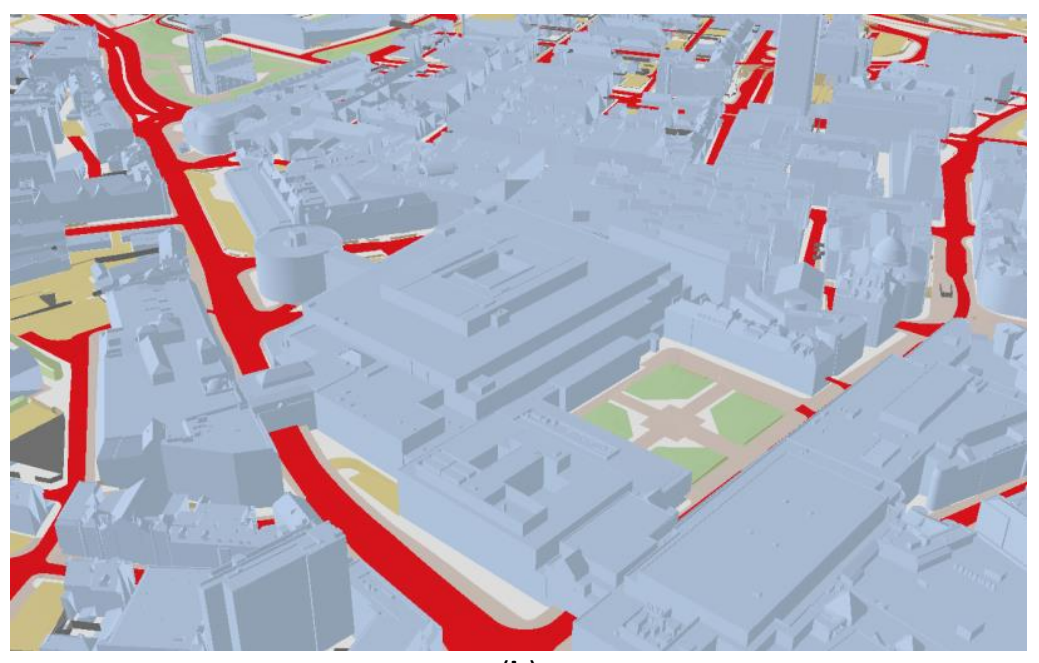

(b) 


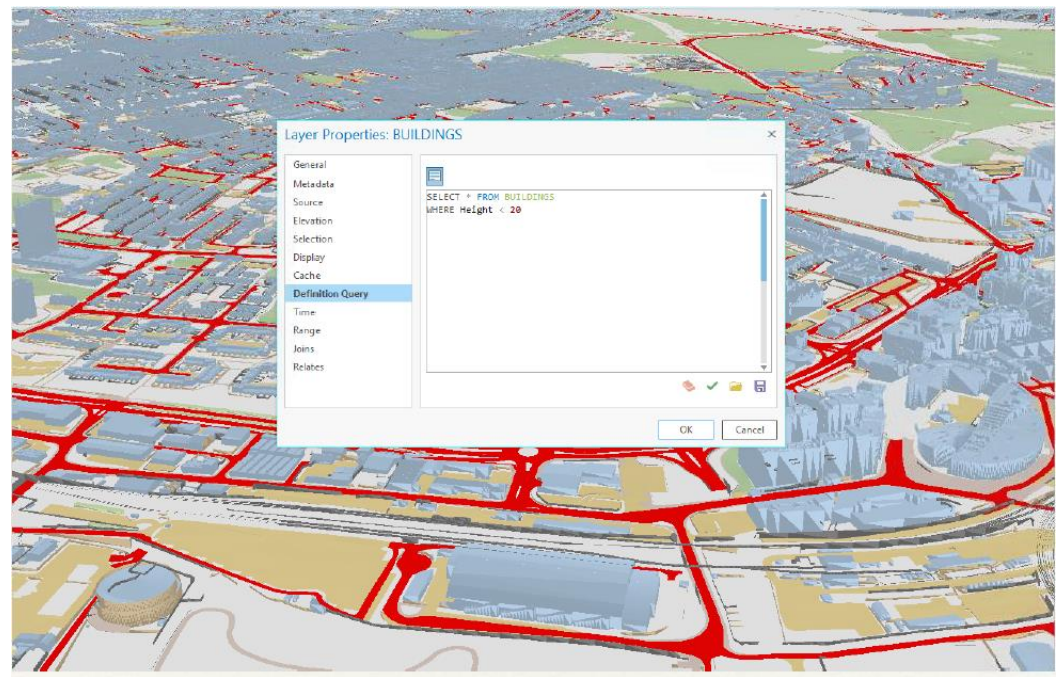

e.g. Select * FROM Buildings WHERE Height <20 AND Ward='Heaton'

(c)

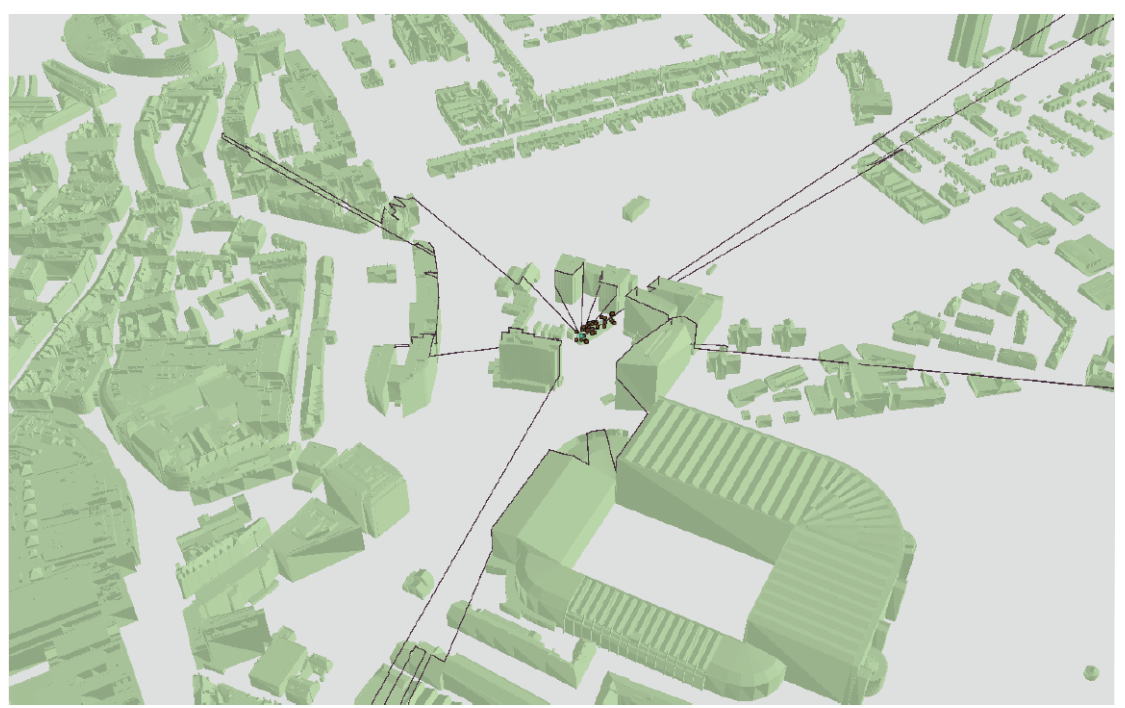

(d)

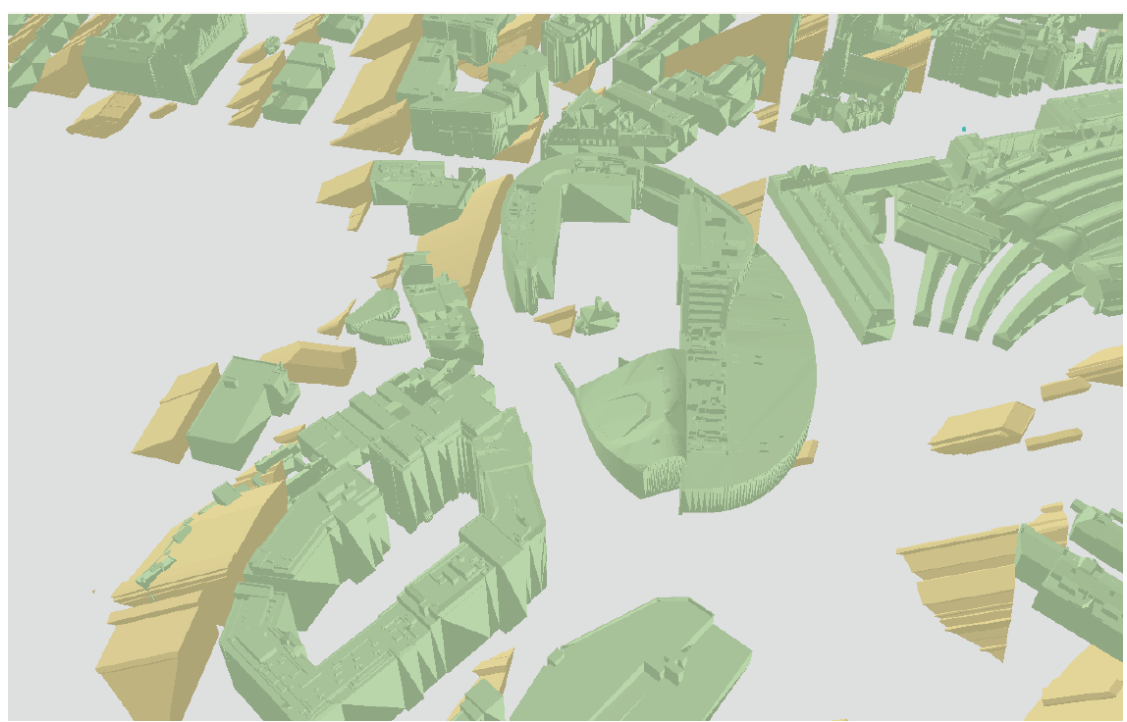

(e) 


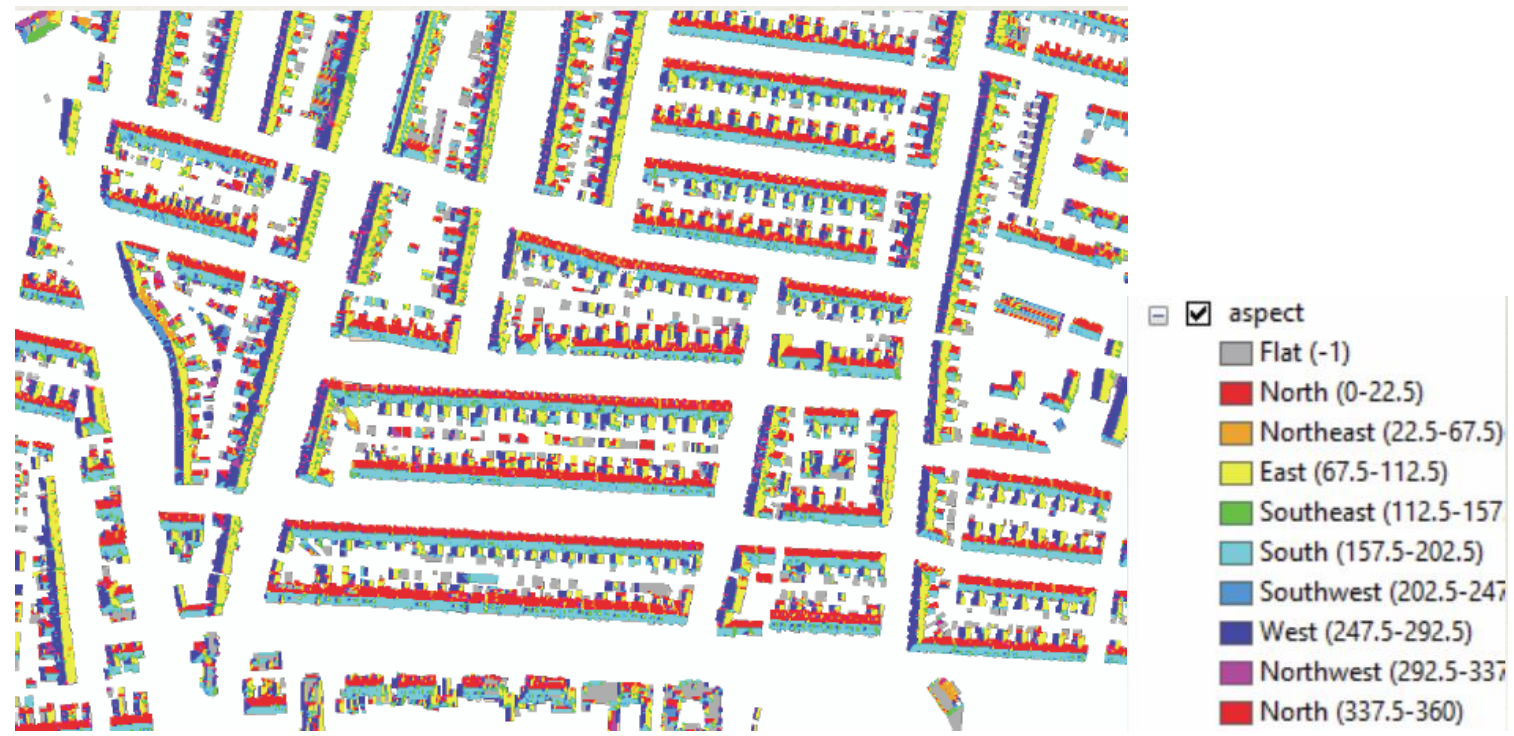

Figure 6. VNG 3D model in GIS platform: (a) Terrain model, (b) VNG in shape file format, (c) Querying in VNG, (d) Skyline analysis, (e) Sun-shadow volume, (f) Analysing roof types (flat etc.) and roof orientation.

This pilot study showed that although problematic, a 3D city model can be enriched with different data types and the resulting new model can be utilized for a variety of analysis that can be used within city planning purposes. Whilst it should be acknowledged that this is a limited experiment it is clear that VNG and other similar virtual city model data sets can be more aligned to the development of the "real" city, allowing both visual and analytical assessment of the urban environment.

\section{Conclusion}

The underlying research question in this paper contemplated how City Information Modelling (CIM) can help planners to influence urban form and the future city and the broader concern of how City Information Modelling (CIM) can be used to help planners as market actors understand and influence urban form and the future city. The evidence and experiences presented in this paper suggests that CIM can be used by Urban Planners and academics to re-engage in urban development as market actors. For instance the emerging research into search preference signals indicates how CIM can be used as a powerful tool to inform the traditional basis of assessing planning applications on 'their own merits' in the UK and recognising and evidencing 'other material considerations' in local areas. Project GV-CREM can be used to substantiate employment premises reviews and allocations of employment land, while Virtual City Models (such as VNG) can be used to interrogate the situational detail of new planning applications. In doing so, CIM can be used to counteract rapidly ageing planning documentation and to influence complex negotiations in relation to viability and developer contributions through the Community Infrastructure Levy (CIL) for example. The central projects indicate how planners can use CIM to model and evidence a better future, for instance by using search preference data to situate new development where occupiers want it. In contrast to the passive records of employment land and premises take up evidenced in traditional employment land studies.

Increasingly, neither state intervention, nor neoliberal market solutions are seen as satisfactory approaches to urban planning challenges. The former is criticised for its managerial inefficiency (see Booth, 2003 for an appraisal of development control and its latter day association with inefficiency) while the latter is criticised for its neglect of external and community interests. Drawing on behavioural and institutional theories of economics and property markets, Adams and Tiesdell (2010) have put forward the argument of planners as 'market actors' where planning practitioners operate confidently within state-market relations. CIM offers an opportunity to answer their call for greater market-rich information and knowledge, however, greater access to information does not automatically mean that planners hold all of the cards, nor should they. Rather, through the development and utilisation of CIM, local planners can play a hands-on role in evidencing and aiding urban change by providing information in relation to potential occupier demand, local infrastructure provision and current land and property availability. This would go some way toward developing a planning intelligence tool which could be used pro-actively in collaboration with the various urban development industries

Summarising our recommendations in the previous sections, we call for a research focus into CIM and the future city around the four key themes that structure this paper. Across the world many cities now have Open Data access sites where a variety of city related 
data can be downloaded by anyone. Research completed in early 2015 shows that, 159 cities in 30 countries across the world have one or more open data access sites. As well as these countries that have city level open data sites another 32 countries have country level open data sites (Thompson, 2015). Illustrating this situation, building and digital terrain models of Berlin can be downloaded for free since 2013. Similarly, geocoded national address data will be made openly available from February 2016 in Australia. These developments show the potential of open data availability. Yet, there is much more to be done before urban planners can fully utilise the full potential of "urban big data" and CIM in spatial planning.

Therefore, firstly, new research and scrutiny must take place in relation to the accessibility and availability of data in the UK. Secondly, it is imperative that steps are taken to improve the accuracy and consistency of data. Thirdly, there is clear and present need for research into the manageability of urban data, particularly in relation to its volume, variety and velocity but also its validity and veracity. Within the latter two points, validity and veracity, resides a wider issue of data ethics in relation to the massive amounts of data, often personal, that is integrated into CIM platforms. In particular the trade offs and $f(r)$ ictions involved in securing the future city through richer urban data and the security and personal integrity of the millions of individuals who volunteer their data, either directly or passively (Marvin et al, 2016). Finally, the ability to integrate urban data is of significant importance. New research must take place into common unique data referencing systems. The Unique Property Reference Numbering (UPRN) system is gaining ascendency in the UK; however, many datasets still do not carry this number. The difficulty outlined in the previous section, involving the merging of project GV-CREM and VNG, demonstrates this complication and the frustration involved in this situation.

Increasingly, both 'big' and 'small' data demands complex systems of storage and analysis. It is no longer enough to assume that data can be stored on a hard drive: distributed systems and the Cloud are increasingly the order of the day while increasingly complex data algorithms are being designed to understand the disparate nature of data. Therefore, the pressing challenge is to understand how these CIM opportunities and challenges can be brought to bear on the spatial planning pursuit in order to evidence and manage the increasingly complex and disparate nature of urban form.

Central to this concern is the acknowledgement that the use of CIM should be circumspect as more data and intelligence alone does not guarantee delivery of a sustainable urban future. Rather, emphasis, and future research, should be placed upon how new market rich intelligence is turned into knowledge through interpretation and use of data. This is because, amidst so much information, there is a risk that big data will provide planners with 'all of the answers' which echoes the unitary master planning tradition in the 1960's which was criticised for its totalitarianism. Consequently, CIM should be approached critically as a tool, rather than as a means of cursory confirmation. Certainly, new opportunities for real time information are seductive but they do not necessarily solve the problems set out earlier in the paper in relation to old data. Rather, the use of CIM provides planers with a new lens for understanding and influencing the perennial challenge of what the city should be.

\section{Acknowledgments}

The authors would like to acknowledge the contributions of Professor Steve Lockley, Professor of Building Modelling, and Martin Cerny, Senior Research Assistant, at Northumbria University

\section{Conflict of Interests}

There are no conflicts of interest.

\section{References}

Adams, D., \& Tiesdell, S. (2010). Planners as market actors: Rethinking state-market relations in land and property. Planning Theory \& Practice, 11(2), 187-207.

Astbury, G., \& Thurstain-Goodwin, M. (2014). Measuring the impact of out-of-town retail development on town centre retail property in England and Wales. Applied Spatial Analysis and Policy, 7(4), 301-316.

Batty, M. (1991). Urban information networks: The evolution and planning of computer-communications infrastructure. In J. F. Brotchie, M. Batty, P. Hall, \& P. Newton (Eds.), Cities of the 21st century: New technologies and spatial systems (pp. 139-157). New York: Halsted Press.

Batty, M. (1997). The computable city. International Planning Studies, 2(2), 155-173.

Batty, M. (2007). Cities and complexity: Understanding cities with cellular automata, agent-based models, and fractals. Cambridge, MA: The MIT press.

Batty, M. (2013). Big data, smart cities and city planning. Dialogues in Human Geography, 3(3), 274-279.

Batty, M., Chapman, D., Evans, S., Haklay, M., Kueppers, S., Shiode, N., \& Hudson-Smith, A. (2000). Visualizing the city: Communicating urban design to planners and decision-makers (CASA Working Papers 32). London, UK: University College London, Centre for Advanced Spatial Analysis.

Batty, M., \& Xie, Y. (1994). From cells to cities. Environment and Planning B: Planning and Design, 21(7), S31-S48.

Baud, I., Scott, D., Pfeffer, K., Sydenstricker-Neto, J., \& Denis, E. (2014). Digital and spatial knowledge man- 
agement in urban governance: Emerging issues in India, Brazil, South Africa, and Peru. Habitat Internacional, 44, 501-509.

Beirão, J. N., Duarte, J. P., Montenegro, N., \& Gil, J. (2009). Monitoring urban design through generative design support tools: A generative grammar for Praia. Proceedings of the APDR Congress. Cidade da Praia, Cabo Verde: APDR.

Bodum, L., Kjems, E., Kolar, J., Ilsøe, P. M., \& Overby, J. (2005). GRIFINOR: Integrated object-oriented solution for navigating real-time 3D virtual environments. In P. J. M. van Oosterom, S. Zlatanova, \& E. M. Fendel (Eds.), Geo-information for disaster management (pp. 937-949). Berlin, Germany: Springer.

Booth, P. (2003). Planning by consent: The origins and nature of British development control. London: Routledge.

Bourdakis, V. (2008). Low tech approach to $3 D$ urban modelling. Paper presented at eCAADe 26, Antwerp.

Charlton, J. (2011). An integrated approach to the design of city centre squares, using three-dimensional computer representations (Doctoral dissertation). Northumbria University, UK.

Charlton, J., Giddings, B., Thompson, E. M., \& Peverett, I. (2015). Understanding the interoperability of virtual city models in assessing the performance of city centre squares. Environment and Planning A, 47(6), 1298-1312.

Clifford, B. P., \& Tewdwr-Jones, M. (2013). The collaborating planner: Planning in the neoliberal age. Bristol, UK: Policy Press.

Dollner, J., \& Hagedorn, B. (2008). Integrating urban GIS, CAD, and BIM data by service-based virtual 3D city models. In M. Rumor, V. Coors, E. Fendel, \& S. Zlatanova (Eds.), Urban and regional data management: Annual 2007 (pp 157-170). London: Taylor \& Francis.

Dollner, J., Kolbe, T. H., Liecke, F., Sgouros, T., \& Teichmann, K. (2006). The virtual 3d city model of Berlin: Managing, integrating and communicating complex information. Paper presented at the 25th International Symposium on Urban Data Management, Aalborg.

Duarte, J. P., Beirão, J. N., Montenegro, N., \& Gil, J. (2012). City Induction: Formulating, generating, and evaluating urban plans. Digital Urban Modelling and Simulation. Communications in Computer and Information Science (CCIS), 242.

Geertman, S., Ferreira Jr, J., Goodspeed, R., \& Stillwell, J. (2015). Introduction to 'planning support systems and smart cities'. In S. Geertman, J. Ferreira Jr., R. Goodspeed, \& J. Stillwell (Eds.), Planning support systems and smart cities (pp. 1-17). Switzerland: Springer International Publishing.

Giddings, B., Charlton, J., \& Horne, M. (2011). Public squares in European city centres. Urban Design International, 16(3), 202-212.
Gil, J., Almeida, J., \& Duarte, J. P. (2011). The backbone of a city information model (CIM). Respecting fragile places: Education in computer aided architectural design in Europe (pp 143-151). Slovenia: eCAADe.

Gil, J., Beirão, J., Moutenegro, N., \& Dunantie, J. (2010). Assessing computational tools for urban design: towards a "city information model". 28th Conference on Future Cities (pp. 316-324). Switzerland: eCAADe

Gil, J., \& Duarte, J. P. (2008). Towards an urban design evaluation framework. Architecture in computro: 26th eCAADe conference proceedings (pp. 257-264). Antwerpen: eCAADe

Gil, J., Duarte, J. P., Beirão, J., Montenegro, N., \& Almeida, J. (2013). The backbone of city information modelling spatial data models and tools for urban design. Paper presented at Pedagogy meets Big Data and BIM Conference, University College London.

Gordon, T., Karacapilidis, N., Voss, H., \& Zauke, A. (1997). Computer-mediated cooperative spatial planning. Decision support systems in urban planning (pp. 299399). London: Spon.

Graham, S., (2004). The cybercities reader (1st ed.). London: Routledge.

Greenhalgh, P. (2008). An examination of business occupier relocation decision making: Distinguishing small and large firm behaviour. Journal of Property Research, 25(2), 107-126.

Greenhalgh, P., Downie, M. L., Fisher, P., \& Barke, M. (2003). Grease to the wheel or a spanner in the works? An investigation of office and industrial occupier displacement and property market filtering in Tyne and Wear using the chaining technique. Regional Studies, 37(4), 381-394.

Greenhalgh, P., \& King, H. (2010). The application of GIS to investigate occupier chains and property market filtering (RICS Research Report). London: RICS.

Greenhalgh, P., \& King, H. (2013).Developing an indicator of property market resilience-investigating the potential of GIS to analyse business occupier displacement and property market filtering: A case study of Tyne and Wear. Urban Studies, 50(2), 372390.

Gröger, G., \& Plümer, L. (2012). CityGML-Interoperable semantic 3D city models. ISPRS Journal of Photogrammetry and Remote Sensing, 71, 12-33.

Guthrie, K. K., \& Dutton, W. H. (1992). The politics of citizen access technology. Policy Studies Journal, 20(4), 574-597.

Hamilton, A., Wang, H., Tanyer, A. M., Arayici, Y., Zhang, X., \& Song, Y. H. (2005). Urban information model for city planning. Journal of Information Technology in Construction, 10, 55-67.

Horne, M. (2009). A tale of two cities: A strategic approach for city modelling on a regional scale. Paper presented at CUPUM09 11th International Conference on Computers in Urban Planning and Urban Management, Hong Kong. 
Horne, M., Thompson, E. M., \& Charlton, J. (2014). Towards a multifunctional virtual city model. In N. Pinto, J. Tenedório, A. Antunes, \& J. Cladera (Eds.), Technologies for urban and spatial planning: Virtual cities and territories. (pp. 154-172). Hershey, PA: IGI Global.

Hudson-Smith, A., Milton, R., Batty, M., Gibin, M., Longley, P. A., \& Singleton, A. D. (2007). Public domain GIS, mapping \& imaging using web-based services. Paper presented at the Third International Conference on e-Social Science, Ann Arbor.

Katyoka, M., \& Wyatt, P. (2008) An investigation of the nature of vacant commercial and industrial property. Planning Practice and Research, 23(1), 125-145.

Khemlani, L. (2007). Autodesk university 2007. AECbytes Newsletter, 32.

Kitchin, R. (2014). The real-time city? Big data and smart urbanism. GeoJournal, 79(1), 1-14.

Lange, E., \& Bishop, I. D. (2005). Visualization in landscape and environmental planning: Technology and applications. London and New York: Taylor \& Francis.

Laurini, R. (2002). Information systems for urban planning: A hypermedia cooperative approach. London and New York: Taylor \& Francis.

Marvin, S., Luque-Ayala, A., \& McFarlane, C. (2016) Smart urbanism: Utopian vision or false dawn? London: Routledge.

Mitchell, W. J. (1995). City of bits: Space, place and the infobahn. Cambridge, MA: MIT Press.

Moir, E., Moonen, T., Clark, G., (2014). What are future cities-Origins, meanings and uses, complied by the business of cities for the foresight future cities project and the future cities. UK Government. Retrieved from https://www.gov.uk/government/uploads/sys tem/uploads/attachment_data/file/337549/14-820what-are-future-cities.pdf

Muldoon-Smith, K., \& Greenhalgh, P. (2015). Passing the buck without the bucks: Some reflections on fiscal decentralisation and the business rate retention scheme in England. Local Economy, 30(6), 609-626.

Morton, P. J., Horne, M., Dalton, R. C., \& Thompson, E. M. (2012). Virtual city models: Avoidance of obsoles- cence. Education and Research in Computer Aided Architectural Design in Europe-30th eCAADe Conference (pp. 213-224). Prague: eCAADe

Muldoon-Smith, K., Greenhalgh, P., Dalton, R., Alvanides, S., King, H., \& Sparkes, B. (2015). Urban transactions: Investigating the relationship between spatial preference and spatial configuration in the city of Leeds. Paper presented at the 10th Space Syntax Symposium (SSS10), London.

Páez, A., \& Scott, D. M. (2005). Spatial statistics for urban analysis: A review of techniques with examples. GeoJournal, 61(1), 53-67.

Shiode, N. (2000). Urban planning, information technology, and cyberspace. Journal of Urban Technology, 7(2), 105-126.

Stojanovski, T. (2013). City information modeling (CIM) and urbanism: Blocks, connections, territories, people and situations. In Proceedings of the Symposium on Simulation for Architecture \& Urban Design ( $p$. 12). San Diego: Society for Computer Simulation International.

Tewdwr-Jones, M. (2012). Spatial planning and governance: Understanding UK planning. London: PalgraveMacmillan.

Thompson, E. M., \& Horne, M. (2010). 3D-GIS integration for virtual Newcastle gateshead. eCAADe 2010 Conference: Future Cities: Proceedings of the 28th Conference on Education in Computer Aided Architectural Design in Europe (pp. 767-775). Zurich: eCAADe.

Thompson, E. M., \& Greenhalgh, P. (2014). Shaping future cities. RICS Land Journal, (Dec/Jan). 14-16.

Thompson, E. M. (2015). City "is" real-time. In Proceedings of the 33rd eCAADe Conference-Volume 1 (pp. 501-510). Vienna: eCAADe

Turley Planning Consultancy. (2015). The Land that time forgot: Planning for employment land. UK: Turley Planning Consultancy.

Wu, H., He, Z., \& Gong, J. (2010). A virtual globe-based $3 D$ visualization and interactive framework for public participation in urban planning processes. Computers, Environment and Urban Systems, 34(4), 291-298.

\section{About the Authors}

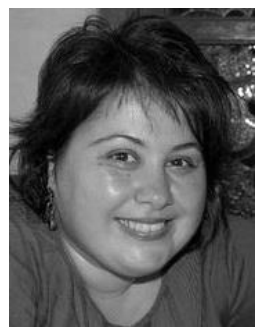

Dr. Emine Mine Thompson

Emine Mine Thompson is senior lecturer in Visualisation and Programme Leader of MSc Future Cities programme at Northumbria University. Her research and teaching interests revolve around visualisation, virtual city modelling, smart/future cities and technologies such as augmented reality, VR and BIM. Recently she led a visualisation project which was part of the Future of Cities Foresight Project. She is a council member of eCAADe and a member of Northumbria University's Virtual Reality and Visualisation Group (VRV). 

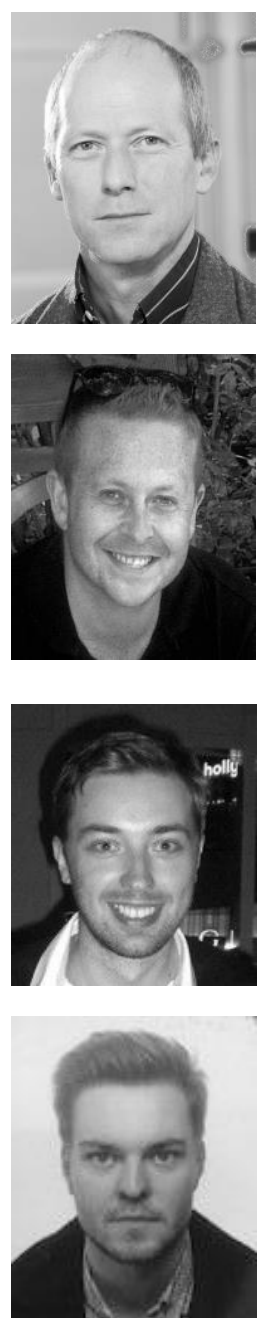

\section{Michal Dolnik}

Michal Dolnik studied GIS/Geomatics at Brno University of Technology, in the Czech Republic, during which he spent atteneded the Geoinformation and Geomatics programme at the Technische Universität Wien in Vienna and spent an internship with the VirtualNewcastleGateshead (VNG) Project Northumbria University. Michal's other work experience includes participation in smart City projects, conversion of 3D CityGML data to 3D GIS, data processing and collection from sensor network and as a developer of GIS web-based applications. 